\title{
Alimentos orgânicos na perspectiva da educação ambiental crítica: uma pesquisa do entendimento de futuros professores de ciências e biologia
}

\author{
Alimentos orgánicos en la perspectiva de la educación ambiental crítica: \\ una investigación del entendimiento de futuros profesores de ciencias y \\ biologia
}

\section{Organic food from the perspective of critical environmental education: a survey of the understanding of future science and biology teachers}

\author{
Débora Anzolin Valginhak ${ }^{1}$ \\ Michael Wellington Sene ${ }^{2}$
}

\begin{abstract}
Resumo
A formação de docentes aptos a abordar temas de influência no cotidiano, como a produção de alimentos, é importante visto o papel da escola de formar cidadãos com consciência crítica da realidade. Sendo assim, realizou-se uma pesquisa com licenciandos em ciências biológicas da UNICENTRO (Guarapuava-Pr) para verificar se esse tema era tratado no curso, o entendimento dos alunos, o interesse em abordá-lo na prática educativa e o conhecimento dos projetos de extensão em agricultura alternativa da universidade. Os dados foram obtidos por meio de questionários e pesquisa documental, tendo que a temática não está presente nas ementas e que os alunos são basicamente jovens do meio urbano, solteiros e sem filhos que reconhecem a importância do tema, mas apresentam conhecimento superficial e não tem noção das atividades realizadas pela universidade.
\end{abstract}

Palavras-Chave: Educação; Formação inicial de professores; Produção de alimentos.

\section{Resumen}

La formación de docentes aptos para abordar temas de influencia en el cotidiano, como la producción de alimentos, es importante visto el papel de la escuela de formar ciudadanos con conciencia crítica de la realidad. Por lo tanto, se realizó una investigación con licenciandos en ciencias biológicas de UNICENTRO (GuarapuavaPr) para verificar si ese tema era tratado en el curso, el entendimiento de los alumnos, el interés en abordarlo en la práctica educativa y el conocimiento de los proyectos de extensión en agricultura alternativa de la universidad. Los datos fueron obtenidos por medio de cuestionarios e investigación documental, teniendo que la temática no está presente en las menús y que los alumnos son básicamente jóvenes del medio urbano, solteros y sin hijos que reconocen la importancia del tema, pero presentan conocimiento superficial y no tienen la noción de las actividades realizadas por la universidad.

Palabras claves: Educación; Formación inicial de professores; Producción de alimentos.

\begin{abstract}
The teacher education able to address issues of influence in everyday life, such as food production, is important given the role of the school to train citizens with a critical awareness of reality. Therefore, a research was carried out with UNICENTRO (Guarapuava-Pr) undergraduates in biological sciences education to verify if this subject was treated in the course, the students' understanding, the interest to approach it in the educational practice and the knowledge of the projects of extension in university alternative agriculture. The data were obtained through

\footnotetext{
${ }^{1}$ Mestranda em Meio Ambiente e Desenvolvimento; Universidade Federal do Paraná-UFPR; Curitiba, paraná; davalginhak@gmail.com.

${ }^{2}$ Doutorando em Geografia; Universidade Estadual do Centro Oeste - UNICENTRO; Guarapuava, Paraná, Brasil; michael_mws03@hotmail.com
} 
questionnaires and documentary research, since the theme is not present in the menus and that the students are basically young people from the urban environment, single and without children who recognize the importance of the subject, but present superficial knowledge and do not have notion of the activities carried out by the university.

Keywords: Education; Food production; Initial teacher education.

\section{Introdução}

A evolução da espécie humana, assim como de qualquer ser vivo, se deu a partir da necessidade em suprir condições básicas de sobrevivência, como obtenção de alimentos, proteção e perpetuação da espécie. Entretanto, durante seu processo evolutivo, houve o desenvolvimento de algumas características singulares que nos distinguiram das outras espécies animais, como certas particularidades morfofisiológicas, a capacidade de transformar a natureza para produção de bens necessários à sua existência, a sociabilidade, a linguagem complexa e a racionalidade (GERALDO, 2014). Todas essas características permitiram ao ser humano obter cada vez mais vantagem na caça e coleta de alimentos, mas ainda mantendo a vulnerabilidade e dependência do estilo de vida nômade, que mudou há aproximadamente 10 mil anos, quando nossa espécie passou a plantar seu próprio alimento, provocando uma grande revolução na forma de organização social, no crescimento populacional e uma profunda modificação do ambiente natural, prática que denominamos de revolução agrícola neolítica (MAZOYER; ROUDART, 2010).

Recentemente, ocasionado a partir do desenvolvimento tecnológico decorrente da Segunda Guerra Mundial, teve início uma nova revolução agrícola que passou a ser denominada de revolução verde e deu origem à agricultura convencional ou moderna. Baseada no melhoramento genético de plantas, na utilização de agrotóxicos e fertilizantes químicos, na intensa mecanização agrícola, na padronização dos métodos de cultivo e sob a justificativa de alimentar a população mundial crescente, essa nova forma de produzir alimentos passou a causar danos à saúde ambiental e animal devido às técnicas empregadas (MAZOYER; ROUDART, 2010). Em oposição à agricultura convencional, surgiram em vários países os sistemas agrícolas de base ecológica ou agricultura alternativa, modelos agrícolas com diferentes características, mas todos baseados em uma produção natural e integrada com o ambiente, tendo como principal objetivo a redução na utilização de insumos e na preferência pelos recursos locais (BORSATO, 2015).

No Brasil, é a agricultura orgânica o sistema de produção de base ecológica mais conhecido e regulamentado por meio da Lei $\mathrm{n}^{\circ} 10.831$, sendo seu objetivo: 
[...] a sustentabilidade econômica e ecológica, a maximização dos benefícios sociais, a minimização da dependência de energia não-renovável, empregando, sempre que possível, métodos culturais, biológicos e mecânicos, em contraposição ao uso de materiais sintéticos, a eliminação do uso de organismos geneticamente modificados e radiações ionizantes, em qualquer fase do processo de produção, processamento, armazenamento, distribuição e comercialização, e a proteção do meio ambiente. (BRASIL, 2003, p. 1).

Além disso, teve surgimento a agroecologia, que segundo Caporal e Azevedo (2011) é uma ciência destinada ao estudo da agricultura sob uma perspectiva ecológica responsável por unir os estudos realizados ao longo dos anos aos saberes históricos dos agricultores, provando que a produção de alimentos pode ser uma prática sustentável.

Após a promulgação da legislação específica para esse tipo de produção em 2003, muito se investiu em políticas de incentivo à agricultura orgânica, tanto em nível federal quanto estadual e municipal, motivados pela busca por um desenvolvimento sustentável (SAMBUICHI et al., 2017). A importância e a preocupação provocada pelas necessidades alimentares mundiais e pela busca por uma agricultura menos perigosa é tanta que "Acabar com a fome, alcançar a segurança alimentar e melhoria da nutrição e promover a agricultura sustentável" se tornou um dos Objetivos do Desenvolvimento Sustentável da ONU (2015).

Sendo assim, concordamos com Matos et al. (2018), que apontam para a importância da educação escolar no sentido de promover o diálogo e a articulação da sociedade em relação a esse tema que se apresenta cada vez mais relevante, discussão necessária não apenas com os estudantes das escolas do campo, como já se espera, mas em todas as modalidades da educação básica, uma vez que somos todos extremamente dependentes dessa prática e que suas temáticas são passíveis de perpassar disciplinas na busca pela tão almejada transformação do modo de ser e viver da sociedade atual, pois como cita o Ministério da Educação nas Diretrizes Curriculares Nacionais da Educação Básica: a formação escolar é a base para o exercício da cidadania e acesso aos direitos sociais, econômicos, civis e políticos, devendo proporcionar o pleno desenvolvimento humano (BRASIL, 2013). Esse enunciado vai ao encontro de Freire (2018, p. 35), que destaca que "educar é substantivamente formar", sendo papel do educador de criar as possibilidades necessárias para a produção ou a construção do conhecimento pelos educandos e que a autonomia do indivíduo só será possível a partir da compreensão de sua responsabilidade na transformação da realidade (BIESDORF, 2011), sendo indispensável a abordagem de assuntos que vão além das disciplinas curriculares para esta finalidade. 
Para contemplar essa formação, foram desenvolvidos mecanismos pelos órgãos responsáveis pela educação no Brasil ao longo dos anos, como os Temas Transversais inseridos nos Parâmetros Curriculares Nacionais, questões importantes presentes na vida cotidiana que deveriam ser incorporados nas disciplinas já existentes de forma a serem priorizados e contextualizados de acordo com as diferentes realidades locais e regionais, sendo eles: Ética, Pluralidade Cultural, Meio Ambiente, Saúde, Orientação Sexual e Trabalho e Consumo (BRASIL, 1998). Em 1999, devido à importância do debate das questões ambientais, foi criada a Política Nacional de Educação Ambiental, passando a ser função da Educação Ambiental (EA) a construção de "valores sociais, conhecimentos, habilidades, atitudes e competências voltadas para a conservação do meio ambiente" (BRASIL, 1999, p. 1), devendo ser obrigatoriamente desenvolvida de forma interdisciplinar, contínua e permanente em todas as modalidades de ensino e níveis da educação escolar, sendo a criação de uma disciplina específica facultativo em cursos de pós-graduação, extensão e quando se fizer necessário, como é o caso das licenciaturas (BRASIL, 1999).

Dessa forma, na EA é possível tratar de diferentes conhecimentos que não se limitem apenas ao ambiente natural, mas também àqueles ligados a ele em suas múltiplas e complexas relações, como a busca pela erradicação da miséria, a justiça social e ambiental e a qualidade de vida, visando a transformação da sociedade. Dessa forma, pesquisas que buscam verificar a compreensão de estudantes sobre aspectos da produção de alimentos ou relatar ações de aproximação dessas crianças e jovens com práticas agrícolas e questões alimentares já vêm apresentando um perceptível crescimento na quantidade de artigos publicados em revistas científicas de educação. Porém, projetos com essa temática ainda não são tão comuns quanto temas mais "fáceis" de serem visualizados no dia a dia das cidades, como foi observado por Trajber e Mendonça (2007), em que basicamente dois temas eram tratados nas práticas de Educação Ambiental das escolas brasileiras: “Água" e "Lixo e Reciclagem”, e que temas como "Práticas agrícolas", "Problemas rurais" e "Saúde e Nutrição" eram raramente abordados, dados que ainda hoje permanecem muito semelhantes (VIEGAS; NEIMAN, 2015). Para Motta e Teixeira (2011), isso acontece porque para muitos professores é incomum ver o aspecto cultural, social, econômico e ambiental presente no ato de se alimentar, aliado ao fato de que $76 \%$ da população brasileira se concentra em municípios considerados predominantemente urbanos (IBGE, 2017) e seu alimento é obtido basicamente em mercados, fazendo com que pouco se questione sobre sua origem. 
Levando em consideração o já mencionado papel da educação, não se pode deixar de citar a importância da formação do profissional docente, pois como cita Teixeira (2007), ao se depararem com assuntos com os quais os professores não obtiveram uma formação prévia, é possível que esses profissionais recorram ao senso comum e acabem repassando informações obtidas de fontes não seguras, o que pode acabar reforçando perspectivas equivocadas e ideologizadas, como ocorre com as questões ambientais. Sendo assim, para suprir a demanda de formação na área ambiental, vários foram os cursos relacionados à temática criados nos últimos anos. Segundo o Ministério da Educação, apenas os programas de pós-graduação stricto sensu na área de Ciências Ambientais tiveram um aumento de 109\% de 2011 a 2015, passando de 73 para 147 cursos interdisciplinares oferecidos (BRASIL, 2016). Entretanto, não apenas a formação continuada é importante, como também a formação inicial, para que os futuros professores concluam a graduação melhor preparados para tratar de assuntos atuais e importantes para a questão socioambiental, pois como lembra Teixeira (2007, p. 100):

\footnotetext{
“[...] não significa que haja uma relação direta entre uma formação mais adequada e a resolução de todos os problemas da chamada educação ambiental. [...] Contudo, o professor 'bem preparado', não só em termos de quantidade de informações, mas de perspectivas de abordagens que o levam a compreensão da complexidade da relação entre a sociedade e seu meio natural, é um professor instrumentalizado para as exigências colocadas no exercício de sua profissão."
}

A partir do exposto por Molon (2016), de que os conceitos de experiência, ou seja, aquilo que é compreendido e significado pelo indivíduo por meio de sua situação vivida, são fundamentais para entender as posições, os lugares e as ações dos sujeitos, pode-se concluir que também exercerá influencia na prática docente. Baseado nessas informações realizou-se uma pesquisa com graduandos do curso de licenciatura em Ciências Biológicas da Universidade Estadual do Centro-Oeste (UNICENTRO) no ano de 2016. O objetivo foi verificar se a problemática da produção de alimentos é tratada no curso; o entendimento dos acadêmicos com relação ao assunto; o interesse em abordá-lo na prática educativa; bem como o conhecimento com relação aos projetos de extensão em agricultura orgânica e agroecologia realizados pela UNICENTRO.

\section{Metodologia}

Foi realizada uma pesquisa exploratória de abordagem quanti-qualitativa, com levantamento de dados por meio da utilização de questionário contendo questões abertas e fechadas e pesquisa documental do currículo do curso para se verificar a existência do tema 
nas ementas das disciplinas. Participaram da pesquisa sessenta e seis acadêmicos dos quatro anos da licenciatura em Ciências Biológicas, estudantes no período noturno na UNICENTRO no ano de 2016 , sendo vinte e três da $1^{\mathrm{a}}$ série $(35 \%)$, vinte e dois da $2^{\mathrm{a}}$ série $(33 \%)$, treze da $3^{\mathrm{a}}$ série $(20 \%)$ e oito da $4^{\mathrm{a}}$ série $(12 \%)$, com idades entre 17 e 35 anos. Esse número amostral está de acordo com a quantidade de acadêmicos presentes em sala e que se dispuseram a responder o questionário no período da pesquisa, que abrangeu quase a totalidade dos acadêmicos matriculados no período. Optou-se por acadêmicos dos diferentes níveis do curso, com o intuito de ter uma visão ampla e diversificada acerca da temática.

A universidade está localizada na cidade de Guarapuava-PR, que apesar de possuir mais de $90 \%$ de sua população residindo no espaço urbano (IBGE, 2011), tem a agricultura comercial ocupando 35,5\% de seu território municipal (GOMES, 2012).

Os questionários foram aplicados durante o horário de aula, com permissão prévia do docente responsável, entre os meses de outubro e novembro de 2016. No questionário continha, além de questões sobre alimentos orgânicos, perguntas referentes a dados pessoais para que fosse possível situar o contexto do pesquisado, bem como traçar um perfil dos participantes da pesquisa. As respostas foram compiladas em planilhas eletrônicas e os dados foram analisados em gráficos e tabelas.

\section{Resultados e discussão}

\subsection{Caracterização dos entrevistados e abordagem do tema no curso}

Com relação à idade, temos que a maioria dos entrevistados possuía entre 18 a 24 anos (53 acadêmicos, 80\%). As idades obtidas podem ser observadas na tabela 1.

Tabela 1 - Distribuição por faixa etária dos pesquisados.

\begin{tabular}{c|c}
\hline \multicolumn{2}{c}{ Faixa etária } \\
\hline Idade & $\mathrm{N}^{\circ}$ de indivíduos (\%) \\
\hline$\leq 22$ & $34(52 \%)$ \\
\hline 22 a 30 & $23(35 \%)$ \\
\hline$\geq 30$ & $1(2 \%)$ \\
\hline Não responderam & $8(12 \%)$ \\
\hline Total & $66(100 \%)$ \\
\hline
\end{tabular}

Fonte: Dados da pesquisa, 2017.

Com relação ao meio de origem dos acadêmicos, a maior parte deles advinha de centros urbanos (47 acadêmicos, $71 \%$ ), fato que os distanciava da produção dos alimentos 
consumidos. Sobre o estado civil e presença ou ausência de filhos pode ser observado na tabela 2.

Tabela 2 - Distribuição por estado civil e presença de filhos.

\begin{tabular}{c|c|c|c|c|c}
\hline \multicolumn{3}{c|}{ Estado civil } & \multicolumn{3}{c}{ Presença de filhos } \\
\hline Solteiro & Casado & Total & Sem filho(s) & Com filho(s) & Total \\
\hline $60(91 \%)$ & $6(9 \%)$ & 66 & $63(95 \%)$ & $3(5 \%)$ & 66 \\
\hline \multicolumn{6}{c}{ Fonte: Dados da pesquisa, 2017. }
\end{tabular}

A partir dos dados apresentados pode-se verificar que os acadêmicos de ciências biológicas da UNICENTRO eram basicamente jovens que nasceram em ambiente urbano, solteiros e sem filhos, público que não faz parte do perfil predominante dos consumidores de orgânicos, que é de indivíduos com 21 até 40 anos, casados e com filhos, pois se pressupões que nessa idade a preocupação com sua saúde e de seu círculo familiar aumenta (LIMA et al., 2015; OLIVEIRA et al., 2015). Além disso, se sabe que a falta de tempo decorrente da rotina universitária faz com que os estudantes universitários mais jovens não apresentem uma alimentação equilibrada, principalmente no que diz respeito ao consumo de frutas e hortaliças (FEITOSA et al., 2010).

Com relação à abordagem do tema no curso, pode-se verificar que apesar da ementa das disciplinas do currículo do curso não conterem especificamente o tema agricultura orgânica ou assuntos relacionados, como transgenia, ação dos agrotóxicos, etc., várias são as disciplinas que podem facilmente abordá-los, como Ecologia Geral, Genética Geral, Genética Molecular, Fisiologia Vegetal e Educação Ambiental (UNICENTRO, 2011), disciplinas obrigatórias a partir do $2^{\circ}$ ano da graduação. Quando questionados se durante o curso já haviam sido abordados esses assuntos, as respostas foram negativas no $1^{\circ}$ ano $\mathrm{e}$ predominantemente positivas pelos acadêmicos do $2^{\circ}, 3^{\circ}$ e $4^{\circ}$ anos, correspondendo a 49 das respostas obtidas (74\%), com temas aparecendo como tópicos isolados dentro dos conteúdos das disciplinas.

\subsection{Definição de alimentos orgânicos e sua relação com a saúde e o Meio Ambiente}

Como já mencionado, podem ser considerados alimentos orgânicos aqueles obtidos por meio do sistema de produção orgânica segundo a definição presente na Lei $n^{\circ}$ 10.831/03. Sendo assim, podemos perceber que essa definição não envolve apenas os alimentos produzidos sem a utilização de insumos químicos, mas todo aquele que seguiu normas visando sua sustentabilidade econômica e ecológica desde a produção até sua comercialização. Com relação a esse conceito, as respostas podem ser observadas na figura 1 . 


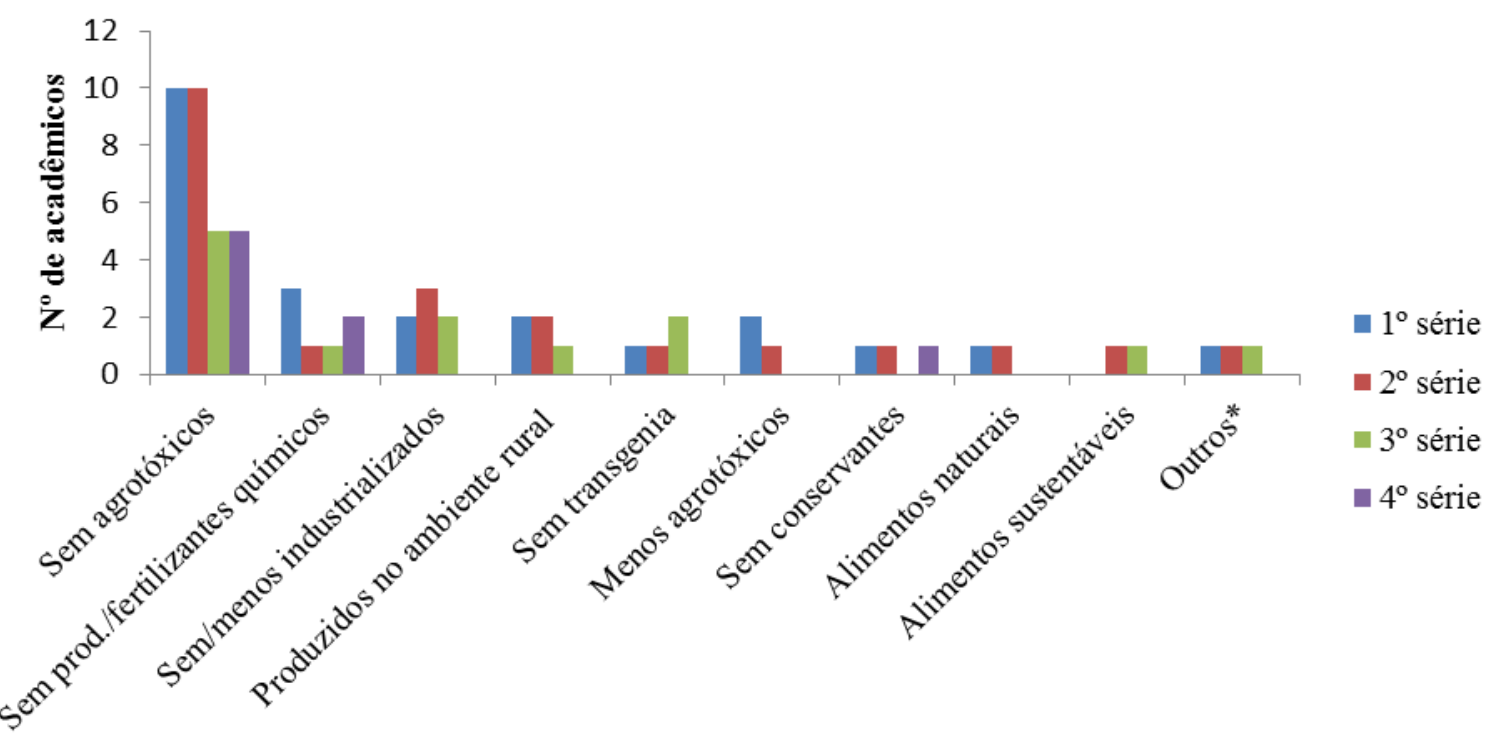

Respostas obtidas

Figura 1 - Conceito de alimento orgânico segundo os entrevistados.

Fonte: Dados da pesquisa, 2017.

*Outros: Alimentos que apodrecem; Constituídos por hidrocarbonetos; Provenientes da agricultura familiar/produção em menor escala.

Observa-se que há certa confusão com relação ao conceito de alimentos orgânicos em todas as séries pesquisadas, mesmo com aquelas onde já ocorreram discussões acerca da temática. Neste contexto, 30 (45\%) estudantes entendem que orgânicos são os alimentos produzidos apenas sem utilização de agrotóxicos e $7(10,6 \%)$ que não se utiliza outros produtos ou fertilizantes químicos em sua produção. Pesquisas com consumidores de orgânicos obtiveram resultados parecidos, mostrando que independentemente do público, grande parte das pessoas associam orgânicos principalmente à ausência de agrotóxicos e posteriormente a não utilização de outros químicos (ANDRADE; BERTOLDI, 2012; LIMA et al., 2015). Essa ligação do termo com apenas uma característica da forma de produção provavelmente ocorre devido à divulgação crescente nas mídias que ocorre de maneira fragmentada, citando, na maioria dos casos, apenas algumas características desse sistema de produção e deixando de lado os inúmeros outros.

Apesar da crescente discussão mundial sobre o tema, uma resposta que chamou atenção foi a de $3(4,5 \%)$ acadêmicos do $1^{\circ}$ e $2^{\circ}$ anos, que mencionaram que o alimento orgânico é produzido com menor utilização de agrotóxicos, mostrando que ainda há pessoas que não creem na possibilidade da produção de alimentos sem a utilização de venenos agrícolas, como se apenas sua redução fosse praticável. Kathounian (2001) lembra que essa mentalidade dependente de agroquímicos ocorre devido ao histórico da agricultura no Brasil, 
que a partir da década de 1970 iniciou a expansão do uso de agrotóxicos juntamente com o exorbitante financiamento aos produtores que se decidiam pelo uso desses pacotes tecnológicos, sendo que as poucas pessoas que se opunham a esse padrão agroquímico eram hostilizadas.

A terceira categoria com maior número de respostas (7 no total, 10,6\%) foi de que esses alimentos não são ou são menos industrializados, sendo considerados naturais. $\mathrm{O}$ conceito de alimentos naturais e industrializados ainda não é bem definido, entretanto os naturais são comumente reconhecidos como os alimentos in natura, no qual não foram adicionados produtos químicos e que não passaram por processos industriais, assim como o alimento industrializado é reconhecido como aquele que passou por algum tipo de processamento, seja ele em larga escala ou doméstico, contendo elementos químicos e não sendo mais tão saudável quanto o natural (OLIVEIRA; MALTA; LIMA FILHO, 2007). Dessa forma, podemos considerar que os vegetais orgânicos podem ser considerados naturais segundo essa definição, mas é preciso lembrar que alimentos orgânicos também podem ser produtos industrializados, como salgadinhos, bolachas, refrigerantes, entre outros inúmeros produtos que estejam de acordo com a instrução normativa $n^{\circ} 24$ de 01 de junho de 2011 (alteração da IN no 18/09), que além de apresentar exigências quanto ao processamento, armazenamento e transporte de produtos orgânicos, estabelece quais aditivos podem ser adicionados a esses alimentos e em quais proporções (BRASIL, 2009).

Outra resposta interessante mencionada por 1 estudante $(1,5 \%)$ foi que são alimentos provenientes da agricultura familiar com produção em menor escala. Machado e Machado Filho (2014) relatam que essa associação ocorre, por vezes, devido aos locais em que esses alimentos são comercializados com maior frequência: as conhecidas feirinhas de produtores ecológicos, um mercado limitado e considerado uma alternativa apenas do ponto de vista individual, mas que esses alimentos podem sim ser produzidos em larga escala.

Apenas 2 acadêmicos $(3 \%)$ da $2^{\mathrm{a}}$ e $3^{\mathrm{a}}$ séries mencionaram a sustentabilidade da produção orgânica, citando mais de uma característica desse sistema e reconhecendo seu menor impacto ambiental. Além disso, todos os acadêmicos afirmaram reconhecer a relação existente entre a agricultura orgânica com a promoção da saúde e a conservação ambiental.

\subsection{Consumo de alimentos orgânicos e conhecimento de projetos extensionistas}


A pesquisa mostrou que apesar de a definição de alimento orgânico não estar muito clara entre os graduandos, grande parte deles afirma consumir esses alimentos com frequência (figura 2).

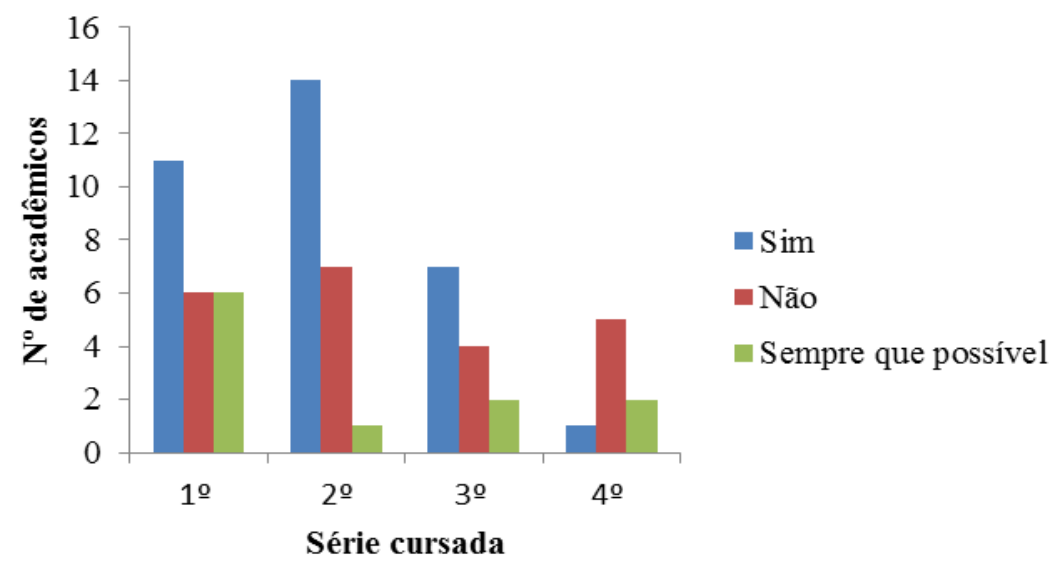

Figura 2 - Consumo de alimentos orgânicos pelos acadêmicos.

Fonte: Dados da pesquisa, 2017.

Do total de alunos entrevistados, 33 (50\%) afirmaram inserir orgânicos na alimentação, sendo que desses, 17 (52\%) consomem por considerar esses alimentos mais saudáveis, seguido por 10 (30\%) que afirmaram se alimentar dessa forma por possuir horta ou familiares que plantam esses alimentos, 2 (6\%) que acreditam que o sabor deles é melhor e 4 (12\%) não responderam. Para Archanjo, Brito e Sauerbeck (2001), as pessoas que dão preferência aos orgânicos pela saúde o fazem por considerar este como um medicamento, considerando essa escolha um investimento.

Entre os 22 (33\%) estudantes que declararam não consumir e 11 (17\%) que consomem sempre que possível, os principais fatores são a inacessibilidade causada pela falta de informação de onde encontrar, o preço e a falta de tempo, com 12 (36\%), 8 (24\%) e 4 (12\%) respostas, respectivamente, e 9 (27\%) não responderam. Sabe-se que nas redes varejistas há uma cobrança superior aos orgânicos, mas essa diferença de preço costuma ser reduzida quando os produtos são adquiridos diretamente com o produtor (BORGUINI; TORRES, 2006).

Com relação à falta de informação sobre locais para compra, a UNICENTRO promove projetos de extensão na área de agricultura orgânica e agroecologia, como a feira agroecológica, realizada com produtores familiares locais nos três campi da universidade, desde 2009, e o Programa Paranaense de Certificação de Produtos Orgânicos, parceria entre a Secretaria da Ciência, Tecnologia e Ensino Superior, o Instituto de Tecnologia do Paraná e as 
Instituições de Ensino Superior do Estado, realizado também desde 2009 e responsável por auxiliar gratuitamente na certificação orgânica dos produtores familiares da região.

Além desses, em 2016, ano da pesquisa, foram aprovadas a continuação de mais dois projetos: "Fortalecimento e difusão da cultura do morangueiro e do fisalis produzidos em sistema orgânico em propriedades familiares" e "Produção de hortaliças orgânicas com certificação participativa visando o autoconsumo, geração de renda e ajustes na qualidade e armazenamento de água para consumo em comunidades rurais de Faxinal, no distrito do Guará em Guarapuava-PR”, ambos com atividades desde 2015. Esses projetos são financiados com recursos estaduais e tem a função de promover uma interação transformadora com outros setores da sociedade e disseminar o conhecimento científico e tecnológico produzido nas instituições acadêmicas. A união das atividades desses projetos já trouxe inúmeros benefícios para a produção familiar e para a segurança alimentar em Guarapuava e região, além da constante atuação nos eventos institucionais por meio de apresentação dos resultados obtidos nos projetos.

Esses projetos ainda oferecem bolsas para graduandos que permitem que o acadêmico possa exercer atividades em outras áreas além da educação, auxiliando na formação de um perfil interdisciplinar, requisito importante para a atuação docente. Entretanto, quando os acadêmicos foram questionados sobre o conhecimento da existência de projetos de extensão relacionados ao tema, $64(97 \%)$ deles disseram não ter conhecimento.

\subsection{Interesse em abordar o tema em sua atuação profissional}

A última pergunta do questionário dizia respeito à opinião por parte dos acadêmicos sobre a necessidade de se abordar o tema alimentos orgânicos e seus assuntos relacionados na escola, apresentando $63(95 \%)$ respostas afirmativas e $3(5 \%)$ respostas em branco, como mostra a figura 3 . 


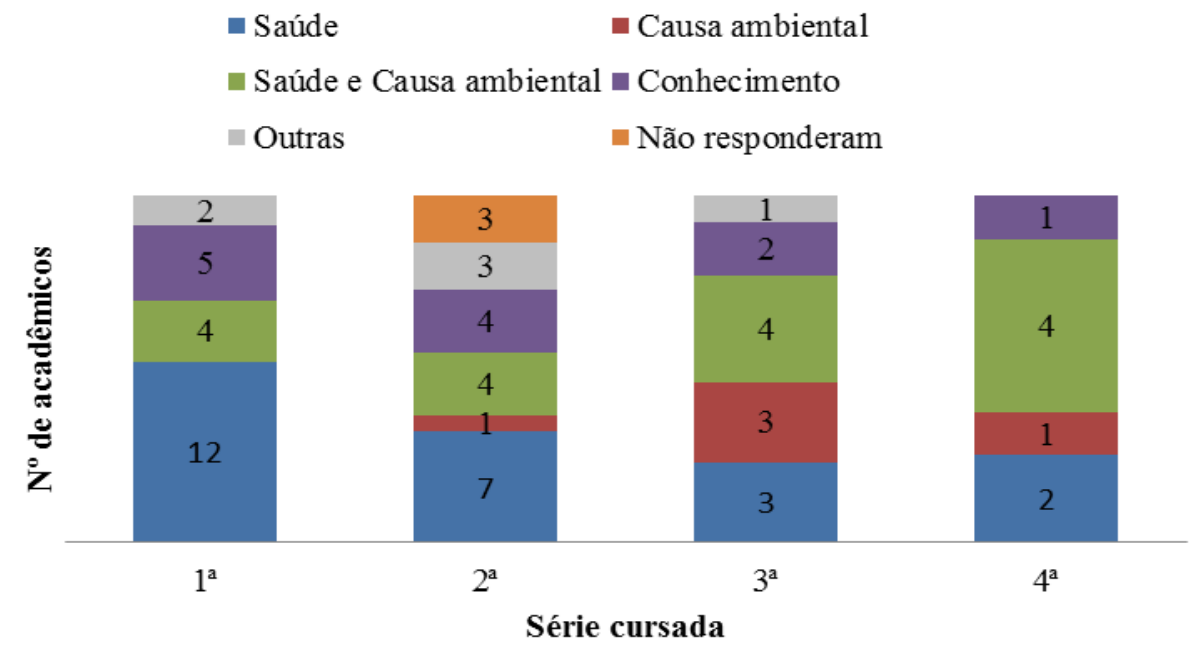

Figura 3 - Interesse em abordar o tema na prática docente.

Fonte: Dados da pesquisa, 2017.

As respostas apresentadas foram separadas por categorias. Do total de acadêmicos, a preocupação com a saúde é a maior motivação apresentada para se abordar o tema na prática docente, com 24 respostas (36\%); a causa ambiental, ou seja, a preocupação com a conservação ambiental, motivaria 5 acadêmicos (8\%); a união entre saúde e meio ambiente motivaria 16 (24\%), o reconhecimento da importância desses conhecimentos na vida dos alunos motivaria 12 acadêmicos (18\%) e outras motivações foram apresentadas por 6 acadêmicos $(9 \%)$.

Dos acadêmicos matriculados na $1^{\mathrm{a}}$ série, $13(52 \%)$ relataram que os alunos precisam entender o que são alimentos orgânicos pela saúde e melhora na qualidade de vida provocada por esses alimentos; 4 (17\%) pela saúde aliada a conservação ambiental; 5 (22\%) também relataram ser necessário "conscientizar" e informar os alunos sobre este tipo de alimentos e 2 (9\%) apresentaram outras motivações.

Dos acadêmicos matriculados na $2^{\mathrm{a}}$ série, 7 (32\%) citaram a saúde como principal motivação; 1 (5\%) citaram as causas ambientais; 4 (18\%) citaram saúde e causas ambientais; 4 (18\%) também citaram a importância do conhecimento; 3 (24\%) deram outras respostas e 3 (14\%) responderam apenas "sim".

Dos acadêmicos matriculados na $3^{\text {a }}$ série, 3 (23\%) seriam motivados pela saúde; 3 (23\%) pela causa ambiental, 4 (31\%) pela união das duas categorias; 2 (15\%) pelo conhecimento e $1(8 \%)$ apresentou outra motivação.

Já dos acadêmicos matriculados na $4^{\text {a }}$ série, 2 (25\%) citaram a saúde; 1 (13\%) a causa ambiental; 4 (50\%) saúde e causa ambiental e 1 (13\%) o conhecimento. 
Algumas respostas serão apresentadas e discutidas a seguir, da forma como foram escritas e seguidas do código do cada entrevistado:

"Sim, com certeza, para a preservação da espécie." (1ª/2).

Os riscos provocados pela agricultura convencional, principalmente pelo uso desenfreado de agrotóxicos, muitas vezes só é lembrado a partir do ponto de vista da saúde humana. Entretanto, seu efeito nos outros animais tem se tornado cada vez mais evidente, principalmente naqueles que mantém contato direto com as plantações pulverizadas e águas contaminadas por agrotóxicos, causando má-formações e até a morte de várias espécies (GREENPEACE, 2017), além dos males causados pela perda de hábitats que passam a ser destinados para o cultivo (FERNANDES-SANTOS et al., 2018).

“Sim, pois orgânicos teoricamente são mais saudáveis." (1ª/4).

Vários estudos comprovam os efeitos nocivos da agricultura convencional, principalmente no Brasil, líder mundial em consumo de agrotóxicos desde 2009 (SPERB, 2016). Para Carneiro et al. (2015) os dados podem ser ainda mais alarmantes, pois esses estudos geralmente investigam a exposição a um único ingrediente ativo, mas na realidade as pessoas estão expostas a dezenas de venenos agrícolas diariamente, como mostra o trabalho de Palma (2011), que constatou a contaminação do leite materno por acumulação no organismo de diversos tipos de agrotóxicos ingeridos pela alimentação das mães.

"Sim, porque os alimentos orgânicos são bem mais saudáveis que os transgênicos. Deve-se haver uma conscientização sobre o tema." (2a/11).

Nesse caso vemos novamente a definição de alimento orgânico ser vinculada a apenas uma característica da produção orgânica, que é a ausência de transgenia. Darnhofer et al. (2010) lembram que a maior importância dada aos produtos do que aos processos tem feito com que os princípios originais da agricultura orgânica sejam distorcidos, deixando de ser a segurança alimentar e se tornando uma simples substituição de insumos aos olhos de muitos.

"Sim, não somente acerca dos produtos orgânicos e seus benefícios, mas também em relação aos problemas sérios causados pela agricultura e pecuária." (4⿳3/3).

Freire (2018) ressalta a importância da discussão da realidade concreta com os alunos na formação de indivíduos críticos. Pode-se visualizar nessa resposta uma iniciativa em abordar temas que, mesmo polêmicos, por se tratar de questões culturais tão arraigadas em 
nossa sociedade, são necessários nas discussões sobre meio ambiente, utilizando-se a definição proposta por Reigota (1995, p. 14): "Lugar determinado ou percebido, onde os elementos naturais e sociais estão em relações dinâmicas e em interação. Essas relações implicam processos de criação cultural e tecnológica e processos históricos e sociais de transformação do meio natural e construído”.

\section{Conclusões}

Mesmo com a recomendação de ser abordada de forma interdisciplinar, muitas vezes a EA acaba se tornando responsabilidade apenas das disciplinas de ciências e biologia, circunstância que motivou a pesquisa. Entretanto, o fato de a agricultura ser uma prática crucial para o desenvolvimento das sociedades e envolver questões passíveis de serem abordadas na formação de indivíduos conscientes da realidade que os cerca, faz com que a abordagem desse tema seja de suma importância nos cursos de licenciatura.

A presente pesquisa envolvendo graduandos da licenciatura em Ciências Biológicas de uma importante universidade do estado do Paraná mostrou que apesar do reconhecimento da importância da temática, esses estudantes apresentam conhecimento extremamente superficial sobre ela, e que em nenhuma das quatro séries do curso ocorre uma real discussão sobre a questão alimentar e suas especificidades. Além disso, os conceitos errôneos apresentados pelos estudantes, aliado à carência na formação, pode fazer com que esses futuros profissionais repassem essas informações incorretas como sendo verdadeiras.

Como o tema não está inserido no currículo do curso, uma alternativa viável seria a realização de palestras e atividades de curta duração até mesmo em parceria com os projetos de extensão atuantes na universidade, permitindo o compartilhamento de saberes e experiências existentes entre os integrantes desses projetos, fazendo com que a tão falada interdisciplinaridade encontrasse seu merecido espaço na formação de professores, não apenas na discussão das questões alimentares, mas de qualquer outro tema em que essa abordagem seja imprescindível.

\section{Referências}

ANDRADE, L. M. S.; BERTOLDI, M. C.. Atitudes e motivações em relação ao consumo de alimentos orgânicos em Belo Horizonte - MG. Braz. J. Food Technol., p. 31-40, 2012. 
ARCHANJO, L. R.; BRITO, K. F. W.; SAUERBECK, S. Alimentos orgânicos em Curitiba: consumo e significado. Cadernos de Debate, v. 8, p. 1-6, 2001.

BIESDORF, R. K. O papel da educação formal e informal: educação na escola e na sociedade. Itinerarius Reflectionis, v. 1, n. 10, p. 1-13, 2011.

BORGUINI, R. G.; TORRES, E. A. F. S. Alimentos orgânicos: qualidade nutritiva e segurança do alimento. Segurança Alimentar e Nutricional, v. 13, n. 2, p. 64-75, 2006.

BORSATO, A. V. Sistema de produção agrícola de base ecológica. In: NUNES, R. R.; REZENDE, M. O. de O. (Org.). Recurso Solo: Propriedades e Usos. São Carlos: Editora Cubo, 2015.

BRASIL. Instrução normativa conjunta $\mathrm{n}^{\circ}$ 18, de 28 de maio de 2009. Aprova o regulamento técnico para o processamento, armazenamento e transporte de produtos orgânicos. Diário Oficial [da] República Federativa do Brasil, Brasília, DF, 28 mai. 2009. Disponível em: < http://planetaorganico.com.br/site/wp-content/uploads/2009/12/in-processamento-280509versc3o-publicada_0.pdf>. Acesso em: 15 mar. 2017.

BRASIL. Lei no 10.831, de 23 de dezembro de 2003. Dispõe sobre a agricultura orgânica e dá outras providências. Diário Oficial [da] República Federativa do Brasil, Brasília, DF, p. 1, 23 dez. 2003. Disponível em:

<https://www.planalto.gov.br/ccivil_03/leis/2003/L10.831.htm>. Acesso em 4 jan. 2019.

BRASIL. Lei no 9.795, de 27 de abril de 1999. Dispõe sobre a educação ambiental, institui a Política Nacional de Educação Ambiental e dá outras providências. Diário Oficial [da] República Federativa do Brasil, Brasília, DF, 28 abr. 1999. Disponível em:

<http://portal.mec.gov.br/secad/arquivos/pdf/educacaoambiental/lei9795.pdf>. Acesso em: 08 jul. 2018.

BRASIL. Ministério da Educação. Coordenação de Aperfeiçoamento de Pessoal de Nível Superior. Documento de Área 2017: Ciências Ambientais. Brasília: MEC/CAPES, 2016. Disponível em:

<http://www.capes.gov.br/images/documentos/Documentos_de_area_2017/49_CAMB_ddoca re_2016_publ2.pdf $>$. Acesso em: 27 mar. 2018.

BRASIL. Ministério da Educação. Diretrizes Curriculares Nacionais Gerais da Educação Básica. Brasília: MEC/SEB/DICEI, 2013.

BRASIL. Ministério da Educação. Parâmetros curriculares nacionais: terceiro e quarto ciclos: apresentação dos temas transversais. Brasília: MEC, 1998.

CAPORAL, F. R.; AZEVEDO, E. O. Princípios e perspectivas da agroecologia. Curitiba: Instituto Federal do Paraná, 2011.

CARNEIRO, F. F.; RIGOTTO, R. M.; AUGUSTO, L. G. S.; FRIEDRICH, K.; BÚRIGO, A. C. (Org.). Dossiê ABRASCO: um alerta sobre os impactos dos agrotóxicos na saúde. São Paulo: Expressão Popular, 2015. 
DARNHOFER, I.; LINDENTHAL, T.; BARTEL-KRATOCHVIL, R.; ZOLLITSCH, W. Conventionalisation of organic farming practices: from structural criteria toward san assessment based on organic principles. Agronomy for Sustainable Development, v. 30, p. 67-81, 2010.

FEITOSA, E. P. S.; DANTAS, C. A. O.; ANDRADE-WARTHA, E. R. S.; MARCELLINI, P. S.; MENDES-NETTO, R. S.. Hábitos alimentares de estudantes de uma universidade pública no Nordeste, Brasil. Alim. Nutr., v. 21, n. 2, p. 225-230, 2010.

FERNANDES-SANTOS, R. C.; MEDICI, E. P.; TESTA-JOSÉ, C.; CANENA, A. C. Impacto de agrotóxicos e metais pesados na anta brasileira (Tapirus terrestres) no estado do Mato Grosso do Sul, Brasil, e implicações para saúde humana e ambiental. 2018. Disponível em: <http://www.ipe.org.br/images/relatorio-agrotoxico-anta.pdf>. Acesso em: 9 jan. 2019.

FREIRE, Paulo. Pedagogia da autonomia: saberes necessários à prática educativa. 56. ed. Rio de Janeiro/São Paulo: Paz e Terra, 2018.

GERALDO, A. C. H. Didática de ciências naturais na perspectiva histórico-crítica. 2. ed. Campinas: Autores Associados, 2014.

GOMES, M. F. V. B. Cartografias da paisagem: trajetória socioambiental de Guarapuava. Guarapuava: UNICENTRO, 2012.

GREENPEACE. Risques environnementaux des pesticides néonocotinö̈des: synthèse des études scientifiques publiées depuis 2013. 2017. Disponível em:

<https://cdn.greenpeace.fr/site/uploads/2017/02/risques_environnements_pesticides.pdf?_ga= 2.149042805.2117101331.1547074366-566774568.1547074366>. Acesso em: 9 jan. 2019.

IBGE. Censo demográfico 2010. 2011. Disponível em:

<http://www.ibge.gov.br/home/presidencia/noticias/imprensa/ppts/0000000402.pdf>. Acesso em: 4 jan. 2019.

IBGE. Classificação e caracterização dos espaços rurais e urbanos do Brasil: uma primeira aproximação. 2017. Disponível em:

<https://biblioteca.ibge.gov.br/visualizacao/livros/liv100643.pdf >. Acesso em: 5 jan. 2019.

KHATOUNIAN, C. A. A reconstrução ecológica da agricultura. Botucatu: Agroecológica, 2001.

LIMA, P. F. C.; LIMA, A. M. M.; CASTRO, S. M. V.; GOMES, M. V. C. N. O consumo de alimentos orgânicos na cidade de Manaus (AM): o comércio de produtos e a sustentabilidade do setor. Revista Verde, v. 10, n. 1, p. 120-127, 2015.

MACHADO, L. C. P.; MACHADO FILHO, L. C. P.. A dialética da agroecologia: Contribuição para um mundo com alimentos sem veneno. São Paulo: Expressão Popular, 2014.

MATOS, N. C. S.; ANDREAZZI, M. A.; GASPAROTTO, F.; LIZAMA, M. A. P.; QUEIRÓZ, F. M.; CAVALIERI, F. L. B. Produção sustentável de alimentos e educação: uma 
relação essencial. Educação Ambiental em Ação, ano 17, n. 65, 2018. Disponível em: < http://revistaea.org/artigo.php?idartigo=3350>. Acesso em: 4 jan. 2019.

MAZOYER, M.; ROUDART, L. História das agriculturas no mundo: do neolítico à crise contemporânea. Tradução de Cláudia Felícia Falluh Balduino Ferreira. São Paulo: Editora UNESP; Brasília: NEAD, 2010.

MOLON, S. I. Constituição do sujeito na formação de professores: significação nas práticas cotidianas. Educação, v. 41, n. 3, p. 567-578, 2016.

MOTTA, M. B.; TEIXEIRA, F. M. Educação alimentar: práticas educativas assumidas no discurso de professoras de ciências. In: ENCONTRO NACIONAL DE PESQUISA EM EDUCAÇÃO EM CIÊNCIAS, 8, 2011, Campinas. Anais eletrônicos. Campinas: UNICAMP, 2011. Disponível em: <http://www.nutes.ufrj.br/abrapec/viiienpec/resumos/R0081-1.pdf>. Acesso em: 9 jan. 2019.

OLIVEIRA, C. S. P.; LIMA, A. F.; SILVA, E. C.; ANDRE, W. P. P.; ANDRE, T. P. P. Produção orgânica: predileção de consumo e potencialidade do seguimento em Fortaleza CE. Revista Verde, v. 10, n. 3, p. 32-36, 2015.

OLIVEIRA, V. R.; MALTA, M. C. M.; LIMA FILHO, D. O. Conceito de alimento natural e alimento industrializado: uma abordagem sócio-comportamental. In: ENCONTRO NACIONAL DE ENGENHARIA DE PRODUÇÃO, 27, 2007, Foz do Iguaçu. Anais eletrônicos. Foz do Iguaçu: ABEPRO, 2007. Disponível em:

<http://www.abepro.org.br/biblioteca/enegep2007_tr610460_9791.pdf>. Acesso em: 9 jan. 2019.

ONU. Transformando nosso mundo: a agenda 2030 para o desenvolvimento sustentável. 2015. Disponível em:

<https://www.mds.gov.br/webarquivos/publicacao/Brasil_Amigo_Pesso_Idosa/Agenda2030.p pd>. Acesso em: 4 jan. 2019.

PALMA, D. C. A. Agrotóxicos em leite humano de mães residentes em Lucas do Rio Verde, MT. Dissertação (Mestrado) - Programa de Pós-Graduação em Saúde Coletiva, Universidade Federal de Mato Grosso, Cuiabá, 2011.

REIGOTA, M. Meio ambiente e representação social. São Paulo: Cortez, 1995.

SAMBUICHI, R. H. R.; MOURA, I. F.; MATTOS, L. M.; ÁVILA, M. L.; SPÍNOLA, P. A. C.; SILVA, A. P. M. A política nacional de agroecologia e produção orgânica no Brasil: uma trajetória de luta pelo desenvolvimento rural sustentável. Brasília: IPEA, 2017.

SPERB, P. 'Epidemia de câncer'? Alto índice de agricultores gaúchos doentes põe agrotóxicos em xeque. BBC Brasil, Porto Alegre, ago. 2016. Disponível em: <http://www.bbc.com/portuguese/brasil-37041324>. Acesso em: 10 abr. 2017.

TEIXEIRA, C. O conhecimento sobre o meio ambiente na formação de professores: uma perspectiva socioambiental. In: DINIS, N. F.; BERTUCCI, L. M. (Orgs.). Múltiplas faces do educar: processos de aprendizagem, educação e saúde, formação docente. Curitiba: Editora UFPR, 2007. 
TRJABER, R.; MENDONÇA, P. R. O que fazem as escolas que dizem que fazem Educação Ambiental? Brasília: SECAD/UNESCO, 2007.

UNICENTRO. Ementário das disciplinas do curso de Ciências Biológicas - licenciatura (currículo iniciado em 2011). 2011. Disponível

em: <http://www2.unicentro.br/proen/files/2016/12/CI\%C3\%8ANCIAS-

BIOL\%C3\%93GICAS-2011.pdf?x34126>. Acesso em: 07 mar. 2017.

VIEGAS, P. L.; NEIMAN, Z. A prática de educação ambiental no âmbito do ensino formal: estudos publicados em revistas acadêmicas brasileiras. Pesquisa em Educação Ambiental, v. 10, n. 2, p. 45-62, 2015. 